in vivo $35: 2875-2880(2021)$

doi:10.21873/invivo.12576

\title{
Ten Daily Fractions for Whole Breast Cancer Irradiation: Long Term Results
}

\author{
LILIANA BELGIOIA ${ }^{1,2}$, ALESSANDRA FOZZA ${ }^{2}$, LUCA TRAPANI $^{1}$, LUCA CARMISCIANO ${ }^{3}$, \\ FRANCESCA CAVAGNETTO ${ }^{4}$, STEFANO AGOSTINELLI $^{4}$, MARINA GUENZI ${ }^{2}$, \\ DANIELE FRIEDMAN ${ }^{5,6}$, PIERO FREGATTI $^{5,6}$ and RENZO CORVÒ ${ }^{1,2}$ \\ ${ }^{1}$ Department of Health Science (DISSAL), University of Genoa, Genoa, Italy; \\ ${ }^{2}$ Radiation Oncology Department, IRCCS Ospedale Policlinico San Martino, Genoa, Italy; \\ ${ }^{3}$ Department of Health Science (DISSAL), Biostatistics Unit, University of Genoa, Genoa, Italy; \\ ${ }^{4}$ Medical Physics Department, IRCCS Ospedale Policlinico San Martino, Genoa, Italy; \\ ${ }^{5}$ Department of Surgical Science and Integrated Diagnostic (DISC), University of Genoa, Genoa, Italy; \\ ${ }^{6}$ Department of Surgery, IRCCS Ospedale Policlinico San Martino, Genoa, Italy
}

\begin{abstract}
Background/Aim: To report the feasibility and oncological outcomes in breast cancer patients treated with a short hypofractionated radiotherapy schedule. Patients and Methods: We evaluated 380 breast cancer patients treated with ten daily fractions of radiotherapy up to 39 Gy on tumor bed. Primary endpoint was local relapse rate (LRR). Secondary endpoints were overall survival (OS) and metastasis-free survival (MFS). Results: The median follow up was 5.0 years. Two- and 5-year LRR rates were 0.2 and $2 \%$, respectively. Two- and 5-year MFS rates were $96.1 \%$ and $90.5 \%$, respectively. Two and 5-year OS rates were $97.4 \%$ and $95 \%$, respectively. Conclusion: This short schedule may represent an alternative option to standard mild hypofractionated radiotherapy in breast cancer patients due to its excellent feasibility and very low recurrence rate.
\end{abstract}

Adjuvant whole breast radiotherapy (RT) after breast conserving surgery (BCS) is the standard treatment in early breast cancer (1). Several data have demonstrated that it reduces the risk of local recurrence and provides a beneficial effect on overall survival with excellent cosmetic results (1). Conventional adjuvant RT fractionation consisted of $50 \mathrm{~Gy}$ in 25 fractions delivered over 5 weeks followed by a boost

This article is freely accessible online.

Correspondence to: Liliana Belgioia (ORCID: 0000-0003-05086344), Department of Health Science (DISSAL), University of Genoa, Via Pastore 1, 16132, Genoa, Italy. Tel: +39 0105558050, e-mail: liliana.belgioia@unige.it

Key Words: Hypofractionated radiotherapy, early breast cancer, adjuvant treatment, local relapse, toxicity. dose of 10-16 Gy or not to the tumor bed (1). In the last decades, alternative radiotherapy schedules were investigated and randomized controlled trials (RCT) have largely tested the efficacy and safety of a hypofractionated RT schedule compared to a conventional regimen $(2,3)$. The increasing interest in reducing the duration of RT with hypofractionated regimens is due to different reasons: the radiobiological one is based on a relative low $\alpha / \beta$ ratio - for breast cancer cells it is estimated to be 4 and then quite close to those of late reacting normal tissues (4); this observation means that breast cancer appears to be sensitive to the fraction size (5). Moreover, it has to be considered that RT is typically delivered after surgery and chemotherapy and is the last part of a multimodality treatment that could even be longer than six months. From this point of view, hypofractionation RT has also potential advantages for patients as it reduces overall treatment time and improves quality of life. Moreover, it leads to a reduction of costs for the healthcare system compared to a standard RT schedule (6). The aim of this work was to report the feasibility and oncological outcomes in a large group of breast cancer patients treated with conservative surgery followed by adjuvant, whole breast intensified hypofractionated regimen, scheduled in 10 fractions.

\section{Patients and Methods}

From November 2012 to January 2016, 380 consecutive early breast cancer patients, treated with BCS and adjuvant RT, were analyzed. Written informed consent to undergo RT was obtained by all patients. The study was approved by Ethics Committee of IRCCS Policlinico San Martino Hospital of Genoa ( $n^{\circ}$ 45/2020).

Radiation treatment. The eligibility criteria for enrollment were the following: age $>44$ years old, histological diagnosis of breast carcinoma, stage pTis-T2, pN0-N1, M0 according to American Joint 
Committee on Cancer Staging Manual, Eighth Edition (2017). Exclusion criteria were: tumor greater than $5 \mathrm{~cm}$ in its largest dimension, 3 or more positive nodes, presence of serious comorbidities that could preclude radiotherapy, previous thoracic irradiation, male patients. The RT regimen was planned either immediately after conservative surgery in low-risk patients or sequentially after chemotherapy in patients at high-risk of disease progression. Each patient received whole breast radiotherapy (WBRT) in 10 fractions of 3.5 Gy (4 fractions a week) to a total dose of 35 Gy. Twice a week, immediately after WBRT, a simultaneous photon boost of $100 \mathrm{cGy}$ was delivered to the lumpectomy area; the total dose to the tumor bed was $38 \mathrm{~Gy}$ in case of negative surgical margins or 39 Gy with close or positive margins. No patients underwent nodal irradiation. Using the linear-quadratic cell survival model and assuming an $\mathrm{a} / \beta$ ratio of $4 \mathrm{~Gy}$ for tumor response (4) and $10 \mathrm{~Gy}$ for acute responding normal tissues (7), we calculated BED for the breast and boost volume in our fractionating schedule, in comparison with the standard and other confirmed treatment schemes (Table I). Definition of target volumes, organ at risks (OARs), and treatment planning were previously described (8).

Follow up. Patients were evaluated at the end of treatment and six months after the end of radiotherapy for radiotherapy-induced normal tissue effects, and then reviewed every year for tumor relapse. Acute toxicity was assessed using the Common Terminology Criteria for Adverse Events (CTCAE version 4.03) (9), and late toxicity using Radiation Therapy Oncology Group (RTOG)/European Organization for Research and Treatment of Cancer (EORTC) scale for radiation-related toxicity (10).

Endpoints. The primary endpoint of this analysis was the local relapse rate (LRR). Secondary endpoints were acute and late toxicity, overall survival (OS) and metastasis-free survival (MFS).

Statistical analysis. Age was summarized with mean and standard deviation (SD). Tumor size and follow-up periods were summarized with median and inter quartile range (IQR) due to their skewed distribution. Categorical variables were summarized with count and percentages. Cox model and Kaplan-Meier method were used to estimate OS and MFS and reported as probability of being event free at 5 years, $95 \%$ confidence interval $(95 \% \mathrm{CI})$, absolute number of events, and number of patients at risk; a competing risks model was used in the estimation of local disease control, considering death as a concurrent event. R software 3.6.0 was used for statistical analysis.

\section{Results}

A total of 380 patients were analyzed. Median follow-up was 5.0 years $(\mathrm{IQR}=4.4-5.6)$. Patient's characteristics are described in Table II. Mean age was seventy years old (range=40-89 years old). About $14 \%$ of the patients had pTis tumor, almost $70 \%$ had pT1, and about $17 \%$ had pT2. Most of the patients were pN0 (73.4\%). $84 \%$ of margins were negative after breast conserving surgery. Also, $77.6 \%$ and $16.6 \%$ of patients received adjuvant hormonal therapy and chemotherapy, respectively. All patients completed the planned RT schedule. At the time of the analysis, five patients had experienced a locoregional recurrence, three patients a nodal recurrence, one
Table I. BED for the breast and boost volume in our fractionating schedule compared with other confirmed treatment schemes.

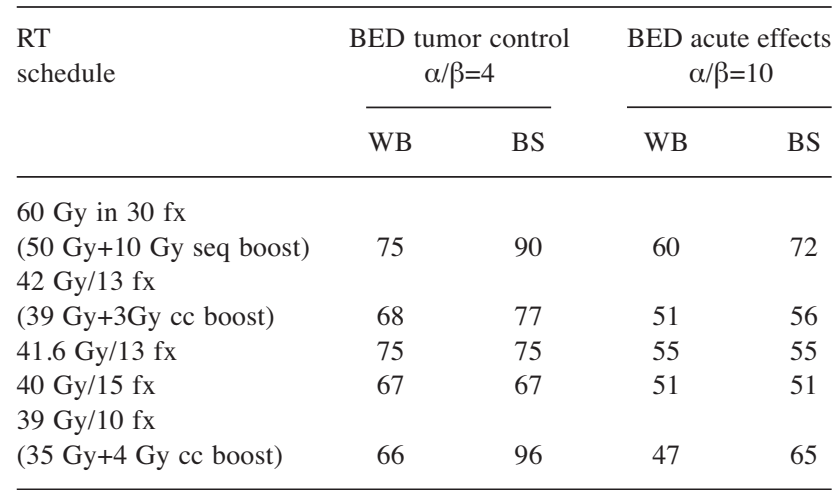

RT: Radiotherapy; WB: whole breast; BS: bed side; BED: biologically effective dose; Gy: Gray, fx: fractions, seq: sequential; cc: concomitant.

patient a breast recurrence, and one patient both breast and nodal recurrence. Twenty-two deceased patients: seven due to metastasis and fifteen due to non-cancer-related causes. Seventeen patients developed distant metastases, mainly in the liver, bone, and lungs. Cumulative incidence of local relapses at 2 and 5 years was $0.8 \%(95 \% \mathrm{CI}=0.01-1.8$, number of relapse events 3$)$ and $2.0 \%(95 \% \mathrm{CI}=0.2-4.0$, number of relapse events 5), respectively (Figure 1). OS at 2 and 5 years was $97.4 \%(95 \% \mathrm{CI}=95.8-99$, number of events 10 , number at risk 369) and 95\% (95\% CI=92.8-97.2, number of events 19 , number at risk 197), respectively (Figure 2). MFS at 2 and 5 years was $96.1 \%(95 \% \mathrm{CI}=94.1-98.1$, number of metastasis or death events 29, number at risk 314) and $90.5 \%$ (95\% CI=87.0-94.0, number of metastasis or death events 29, number at risk 65), respectively (Figure 3 ). In regard to acute toxicity, at the end of the treatment, 155 (40.8\%) patients presented G0 erythema, 188 (49.5\%) G1 erythema, 35 (9.2\%) $\mathrm{G} 2$ erythema, and $2(0.5 \%) \mathrm{G} 3$ erythema. Only six patients presented mild edema (Table III). At six months, 71 patients presented G1 fibrosis, 18 G2 fibrosis, and only two patients presented G3 fibrosis. In twenty cases there was a slight erythema or hyperpigmentation; in twenty other cases there was a slight/modest scar retraction. Edema and lymphedema were present in nine cases (Table III).

\section{Discussion}

Whole breast RT is the standard of care in patients with early cancer after BCS (1). In 2015, a meta-analysis by Budach et al. identified four RCT (START Pilot, START A, START B and Ontario) that evaluated hypofractionated RT compared to conventional fractionated RT. All these trials concluded that hypofractionated RT can be safely used in early breast cancer patients as it leads to similar oncological outcomes with no 
Table II. Patient characteristics.

\begin{tabular}{|c|c|}
\hline Mean age, YRS (SD) & $70.00[9.56]$ \\
\hline Menopause, N (\%) & 348 (91.6) \\
\hline \multicolumn{2}{|l|}{ Tumor class (AJCC), N (\%) } \\
\hline pTis & $53(13.9)$ \\
\hline pT1 & $261(68.7)$ \\
\hline pT2 & $66(17.4)$ \\
\hline \multicolumn{2}{|l|}{ Nodal class (AJCC), N (\%) } \\
\hline pNO & $279(73.4)$ \\
\hline $\mathrm{pN} 1$ & $58(15.3)$ \\
\hline $\mathrm{pNx}$ & $43(11.3)$ \\
\hline \multicolumn{2}{|l|}{ Grading N (\%) } \\
\hline 1 & $62(16.8)$ \\
\hline 2 & 257 (69.6) \\
\hline 3 & $50(13.6)$ \\
\hline $\begin{array}{l}\text { Tumour sizer, MM Median } \\
\text { [IQR] }\end{array}$ & $\begin{array}{c}14.00 \\
{[8.23,19.00]}\end{array}$ \\
\hline \multicolumn{2}{|l|}{ Side, N (\%) } \\
\hline Right & $178(46.8)$ \\
\hline Left & $200(52.6)$ \\
\hline Bilateral & $2(0.5)$ \\
\hline \multicolumn{2}{|l|}{ Margins, N (\%) } \\
\hline Positive & $14(3.7)$ \\
\hline Negative & $322(84.7)$ \\
\hline Close & $44(11.6)$ \\
\hline Ki67 index $>20 \%, \mathrm{~N}(\%)^{*}$ & $120(36.1)$ \\
\hline \multicolumn{2}{|l|}{ Adjuvant CT, N (\%) } \\
\hline Yes & $63(16.6)$ \\
\hline Not & $317(83.4)$ \\
\hline \multicolumn{2}{|l|}{ Adjuvant OT, N (\%) } \\
\hline Yes & $295(77.6)$ \\
\hline Not & 85 (22.4) \\
\hline \multicolumn{2}{|l|}{ Hormone receptor, $\mathrm{N}(\%)$} \\
\hline \multicolumn{2}{|l|}{ ER } \\
\hline Positive & $322(84.7)$ \\
\hline Negative & $35(9.2)$ \\
\hline Not evaluated** & $23(6.1)$ \\
\hline \multicolumn{2}{|l|}{$\mathrm{PgR}$} \\
\hline Positive & $285(75.0)$ \\
\hline Negative & $71(18.7)$ \\
\hline Not evaluated $* *$ & $24(6.3)$ \\
\hline \multicolumn{2}{|l|}{ Her2 } \\
\hline Positive & $20(5.2)$ \\
\hline Negative & $313(82.4)$ \\
\hline Not evaluated** & $47(12.4)$ \\
\hline \multicolumn{2}{|c|}{ Immunophenotypic groups, $\mathrm{N}(\%) * * *$} \\
\hline Luminal A & $184(48.4)$ \\
\hline Luminal B/Her2+ & $8(2.1)$ \\
\hline Luminal B/Her2- & $92(24.2)$ \\
\hline Non-Luminal/Her2+ & $6(1.6)$ \\
\hline Triple Negative & $25(6.6)$ \\
\hline
\end{tabular}

YRS: Years; N: number; MM: millimeter; CT: chemotherapy; OT: hormonal therapy; ER: estrogen; PgR: progesterone. *not evaluable in 48 patients; **not reported on histological examination (ex. in pTis tumor); ***not evaluable in 65 patients (due to the lack of one or more biological data). increase in late toxicity (11). More recently, a 2016 Cochrane review on hypofractionated RT for early breast cancer confirmed the same conclusions both for oncological results and for acute and late toxicities and quality of life (12). Today, therefore, these data allow us to consider hypofractionation as an effective option in adjuvant breast RT (13). In fact, RCT as START A have shown that $41.6 \mathrm{~Gy} / 13$ fractions or $39 \mathrm{~Gy} / 13$ fractions are similar to the control regimen of $50 \mathrm{~Gy} / 25$ fractions in terms of local-regional tumor control and late normal tissue effects; similarly, the START trial B, which randomized 2,215 women with early breast cancer (pT1-3a pN0-1 M0) to a radiation scheme of $40 \mathrm{~Gy} / 15$ fractions or 50 $\mathrm{Gy} / 25$ fractions, reported a rate of local-regional tumor relapse at 5 years of $2.2 \%$ in the 40 Gy group and $3.3 \%$ in the 50 Gy group after a median follow-up of 6.0 years (14). An update at 10 years after these two English trials showed that localregional relapse did not differ significantly between the hypofractionated schemes and standard regimen groups (3). In our analysis, we proposed this new intensified scheme that showed a very low mid-term recurrence rate similar to those reported with other consolidated fractionations. A similar ten fraction schedule was explored by Trovò et al. using partial breast irradiation (PBI). Outcomes recently published (15) showed excellent results in outcome and feasibility. Although results from a randomized trial (16) seem to establish the role of PBI, this modality is not largely adopted and WBI remains the most adopted in clinical practice. Comparing our 5 years results obtained by short hypofractionated WBI with those obtained from the START-A and START-B trials the LRR are similar: $3.5 \%$ after $41.6 \mathrm{~Gy}, 5.2 \%$ after 39 Gy (START-A, 13 fractions), $2.2 \%$ after 40 Gy (START-B, 15 fractions) and $2 \%$ after 35 Gy (Genoa Trial, 10 fractions). Stronger hypofractionated schedules were recently introduced in the FAST and FAST Forward trials, two 3-arm randomized control phase III trials. The first compared standard fractionation (50 Gy/25 fractions) with 5.7/6 Gy $\times 5$ fractions delivered once a week and reported incidence rates for ipsilateral breast events of $0.7 \%$ at 5 years (even if the trial was not powered for comparison of recurrence rates, primary endpoint changed in breast appearance at 2 and 5 years) (17). The FAST Forward trial evaluated ultra hypofractionated schedules (5.2/5.4 Gy $\times 5$ consecutive fractions $v s$. START B arm) with an estimated cumulative incidence rate of ipsilateral breast tumor relapse at 5 years of $2.1 \%$ for the standard arm, $1.7 \%$ for $27 \mathrm{~Gy}$, and $1.4 \%$ for 26 Gy (no difference) (18). In our center, we have used hypofractionated RT for breast cancer for several years; a hypofractionation of $46 \mathrm{~Gy}$ in 20 fractions $(19,20)$ and 39 Gy in 13 fractions (8) have been carried out since 2007 and 2008, respectively, showing a reasonable good feasibility in terms of safety, efficacy, acute and subacute toxicity, in line with the British studies. Only in elderly women (over 70 years old) we are now adopting an extreme hypofractionation scheme (5.7 Gy $\times 5$ weekly fractions) (21) according to the latest NCCN 


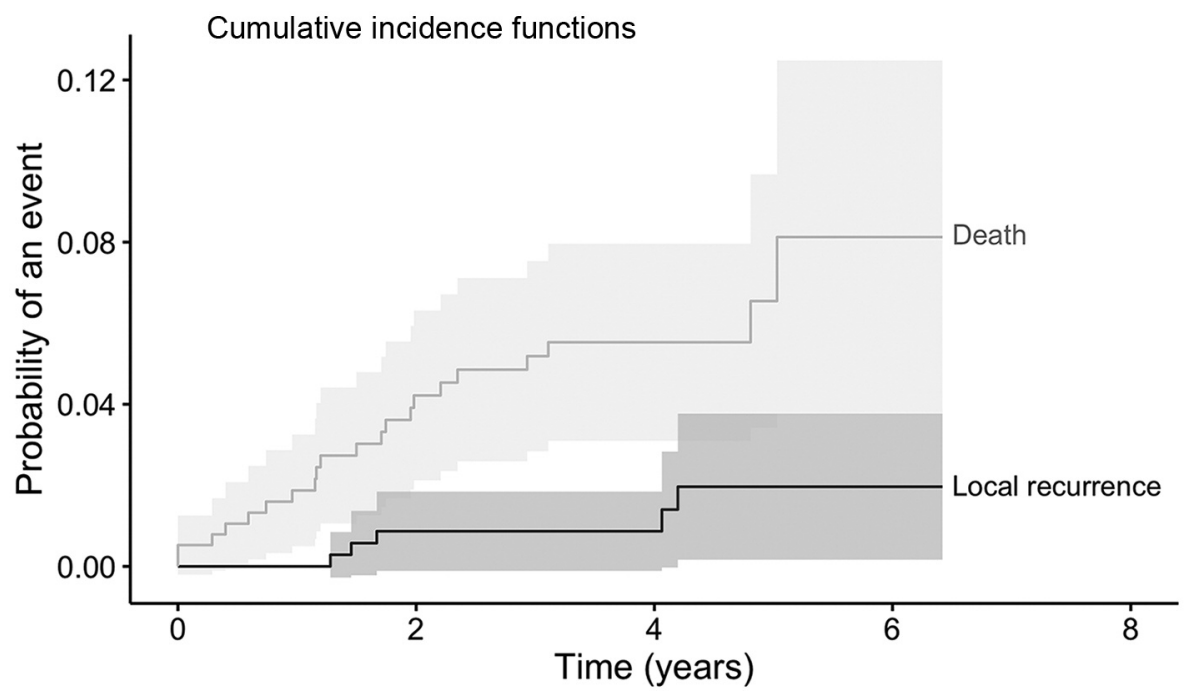

Figure 1. Cumulative incidence of local recurrence and death. Kaplan-Meier curve describing the risk of local recurrence and the risk of death.

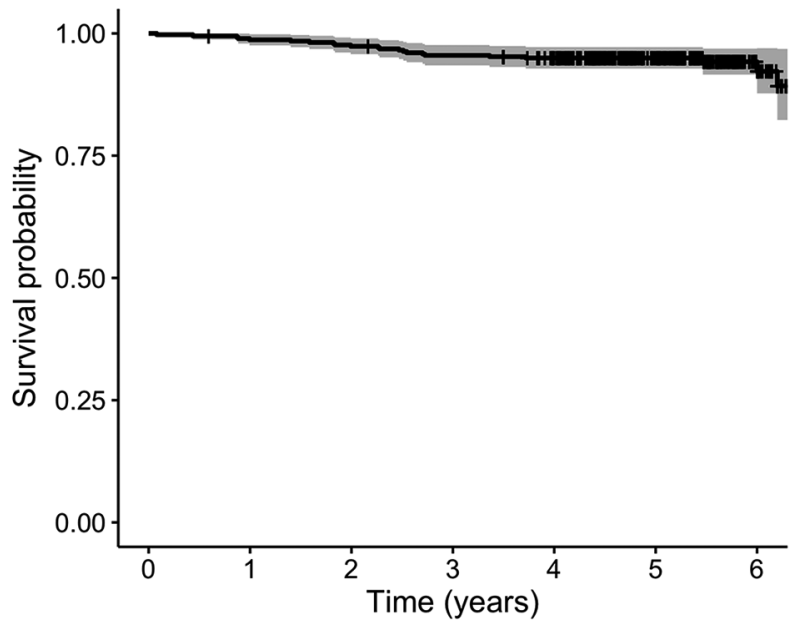

Number at risk

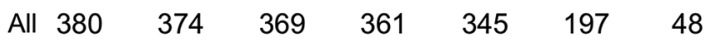

Figure 2. Kaplan-Meier curve describing overall survival.

guidelines that suggest this schedule (28.5 Gy in 5 fractions once a week) only for selected patients (22). We underline that long-term data on toxicity from extreme hypofractionation schedules were not well defined; both in the FAST and FAST Forward trials moderate and marked late effects were increased in the experimental arm. Moreover, in the FAST Forward trial, the relative risk for any moderate and marked late effects increased over time, indicating that longer follow-up is necessary to evaluate the long-term safety of this regimen (23). In regard to acute and late toxicities, our analysis showed low grade side effects to the skin and subcutaneous tissues. At the

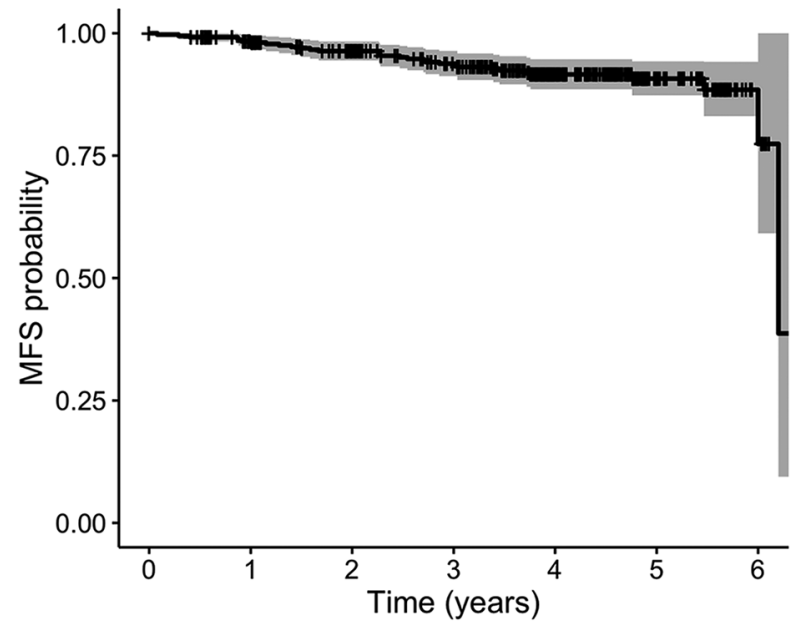

Number at risk

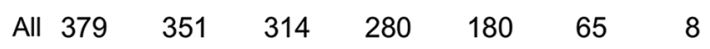

Figure 3. Kaplan-Meier curve describing metastasis-free survival.

end of the treatment, about half of the patients presented mild erythema; only two reported a grade 3 skin toxicity. Six months after the end of the treatment, $5 \%$ of the patients had mild hyperpigmentation and about $18 \%$ mild fibrosis. Only $0.5 \%$ reported G3 fibrosis.

Despite the limitations of this study due to its retrospective design, the initial analysis of the late effects appears promising. This seems in line with the results of other important studies in the literature (24-26). Another interesting point is that our scheme provides the administration of a simultaneous boost in all patients (27); this is different from 
Table III. Acute and late toxicity.

\begin{tabular}{|c|c|c|c|c|}
\hline Acute toxicity & G0 & G1 & $\mathrm{G} 2$ & G3 \\
\hline Erythema & $\begin{array}{c}155 \\
(40.8 \%)\end{array}$ & $\begin{array}{c}188 \\
(49.5 \%)\end{array}$ & $\begin{array}{c}35 \\
(9.2 \%)\end{array}$ & $\begin{array}{c}2 \\
(0.5 \%)\end{array}$ \\
\hline Edema & $\begin{array}{c}374 \\
(98.4 \%)\end{array}$ & $\begin{array}{c}6 \\
(1.6 \%)\end{array}$ & $\begin{array}{c}0 \\
(0 \%)\end{array}$ & $\begin{array}{c}0 \\
(0 \%)\end{array}$ \\
\hline Late toxicity & G0 & G1 & G2 & G3 \\
\hline $\begin{array}{l}\text { Erythema/ } \\
\text { Hyperpigmentation }\end{array}$ & $\begin{array}{c}360 \\
(94.7 \%)\end{array}$ & $\begin{array}{c}20 \\
(5.3 \%)\end{array}$ & $\begin{array}{c}0 \\
(0 \%)\end{array}$ & $\begin{array}{c}0 \\
(0 \%)\end{array}$ \\
\hline Edema/Lymphedema & $\begin{array}{c}371 \\
(97.6 \%)\end{array}$ & $\begin{array}{c}9 \\
(2.4 \%)\end{array}$ & $\begin{array}{c}0 \\
(0 \%)\end{array}$ & $\begin{array}{c}0 \\
(0 \%)\end{array}$ \\
\hline Fibrosis & $\begin{array}{c}289 \\
(76.1 \%)\end{array}$ & $\begin{array}{c}71 \\
(18.7 \%)\end{array}$ & $\begin{array}{c}18 \\
(4.7 \%)\end{array}$ & $\begin{array}{c}2 \\
(0.5 \%)\end{array}$ \\
\hline Scar retraction & $\begin{array}{c}356 \\
(93.7 \%)\end{array}$ & $\begin{array}{c}20 \\
(5.3 \%)\end{array}$ & $\begin{array}{c}0 \\
(0 \%)\end{array}$ & $\begin{array}{c}0 \\
(0 \%)\end{array}$ \\
\hline
\end{tabular}

those of the aforementioned randomized trials where a boost dose was not administered or it was delivered with a standard fractionation; even in the FAST Forward trial a sequential boost with 5-8 fractions of 2 Gy was applied, but this led to double the overall treatment time. It is well known that tumor bed is the area at highest risk for persistent microscopic disease and a local dose escalation has proven to decrease the in-breast recurrence rates most effectively, especially in younger women (28). Moreover, we chose to adjust boost dose according to the margin status (4 Gy in 4 fractions for patients with positive or close margins and $3 \mathrm{~Gy}$ in 3 fractions in negative margins) in order to reduce the risk of local relapse.

This study also has other limitations, including the lack of a comparison arm in the analysis; however, to date, this hypofractionated schedule can be easily prescribed and delivered in early breast cancer both for radiobiological rationale, technological innovations, and logistic reasons. In conclusion, this intensified radiation schedule, delivered in ten fractions, offers excellent outcome and may provide an alternative option to conventional WBI, providing similar results in terms of disease control with a satisfactory quality of life for women during and after treatment.

\section{Conflicts of Interest}

The Authors declare that they have no conflicts of interest.

\section{Authors' Contributions}

LB: wrote the paper, and reviewed final manuscript. LT: data collection. FC and SA: review and editing of final manuscript. Provided insight into how results relate to treatment planning. LC: data analysis, ran all statistical tests. $\mathrm{RC}, \mathrm{AF}$ and MG: review and editing of final manuscript and provided insight into how results relate to radiation oncology. DF and PF: review and editing of final manuscript and provided insight into how results relate to surgical oncology. All Authors approved the final version of the manuscript.

\section{References}

1 Early Breast Cancer Trialists' Collaborative Group (EBCTCG), Darby S, McGale P, Correa C, Taylor C, Arriagada R, Clarke M, Cutter D, Davies C, Ewertz M, Godwin J, Gray R, Pierce L, Whelan T, Wang Y and Peto R: Effect of radiotherapy after breastconserving surgery on 10-year recurrence and 15-year breast cancer death: meta-analysis of individual patient data for 10,801 women in 17 randomised trials. Lancet 378(9804): 1707-1716, 2011. PMID: 22019144. DOI: 10.1016/S0140-6736(11)61629-2

2 Whelan TJ, Pignol JP, Levine MN, Julian JA, MacKenzie R, Parpia S, Shelley W, Grimard L, Bowen J, Lukka H, Perera F, Fyles A, Schneider K, Gulavita S and Freeman C: Long-term results of hypofractionated radiation therapy for breast cancer. N Engl J Med 362(6): 513-520, 2010. PMID: 20147717. DOI: 10.1056/NEJMoa0906260

3 Haviland JS, Owen JR, Dewar JA, Agrawal RK, Barrett J, BarrettLee PJ, Dobbs HJ, Hopwood P, Lawton PA, Magee BJ, Mills J, Simmons S, Sydenham MA, Venables K, Bliss JM, Yarnold JR and START Trialists' Group: The UK Standardisation of Breast Radiotherapy (START) trials of radiotherapy hypofractionation for treatment of early breast cancer: 10-year follow-up results of two randomised controlled trials. Lancet Oncol 14(11): 1086-1094, 2013. PMID: 24055415. DOI: 10.1016/S1470-2045(13)70386-3

4 Owen JR, Ashton A, Bliss JM, Homewood J, Harper C, Hanson J, Haviland J, Bentzen SM and Yarnold JR: Effect of radiotherapy fraction size on tumour control in patients with early-stage breast cancer after local tumour excision: long-term results of a randomised trial. Lancet Oncol 7(6): 467-471, 2006. PMID: 16750496. DOI: 10.1016/S1470-2045(06)70699-4

5 Hennequin $\mathrm{C}$, Guillerm $\mathrm{S}$ and Quero $\mathrm{L}$ : Rationale for hypofractionation. Cancer Radiother 23(6-7): 500-502, 2019. PMID: 31444076. DOI: 10.1016/j.canrad.2019.07.156

6 Rivera S and Hannoun-Lévi JM: Hypofractionated radiation therapy for invasive breast cancer: From moderate to extreme protocols. Cancer Radiother 23(8): 874-882, 2019. PMID: 31611051. DOI: 10.1016/j.canrad.2019.09.002

7 Fowler JF: 21 years of biologically effective dose. Br J Radiol 83(991): 554-568, 2010. PMID: 20603408. DOI: 10.1259/bjr/ 31372149

8 Corvò R, Ricchetti F, Doino D, Torielli P, Agostinelli S, Cavagnetto F, Giannelli F, D'Alonzo A, Vagge S, Belgioia L and Guenzi M: Adjuvant hypofractionated radiotherapy with weekly concomitant boost for women with early breast cancer: the clinical experience at Genoa university. Anticancer Res 30(11): 4749-4753, 2010. PMID: 21115935

9 Common Terminology Criteria for Adverse Events (CTCAE) I Protocol Development I CTEP. Available at: https://ctep. cancer.gov/protocolDevelopment/electronic_applications/ctc.htm \#ctc_40 [Last accessed on January 15, 2020]

10 RTOG/EORTC Late Radiation Morbidity Scoring Schema. Available at: https://www.rtog.org/ResearchAssociates/Adverse EventReporting/RTOGEORTCLateRadiationMorbidityScoringSc hema.aspx [Last accessed on January 15, 2020]

11 Budach W, Bölke E and Matuschek C: Hypofractionated radiotherapy as adjuvant treatment in early breast cancer. A 
review and meta-analysis of randomized controlled trials. Breast Care (Basel) 10(4): 240-245, 2015. PMID: 26600759. DOI: $10.1159 / 000439007$

12 Hickey B, James M, Lehman M, Hider P, Jeffery M, Francis D and See A: Hypofractionated radiation therapy for early breast cancer. Cochrane Database of Systematic Reviews, 2021. DOI: 10.1002/14651858.CD003860.pub4

13 Smith B, Bellon J, Blitzblau R, Freedman G, Haffty B, Hahn C, Halberg F, Hoffman K, Horst K, Moran J, Patton C, Perlmutter J, Warren L, Whelan T, Wright J and Jagsi R: Radiation therapy for the whole breast: Executive summary of an American Society for Radiation Oncology (ASTRO) evidence-based guideline. Practical Radiation Oncology 8(3): 145-152, 2020. DOI: $10.1016 /$ j.prro.2018.01.012

14 START Trialists' Group, Bentzen SM, Agrawal RK, Aird EG, Barrett JM, Barrett-Lee PJ, Bliss JM, Brown J, Dewar JA, Dobbs HJ, Haviland JS, Hoskin PJ, Hopwood P, Lawton PA, Magee BJ, Mills J, Morgan DA, Owen JR, Simmons S, Sumo G, Sydenham MA, Venables $K$ and Yarnold JR: The UK Standardisation of Breast Radiotherapy (START) Trial A of radiotherapy hypofractionation for treatment of early breast cancer: a randomised trial. Lancet Oncol 9(4): 331-341, 2008. PMID: 18356109. DOI: 10.1016/S1470-2045(08)70077-9

15 Vinante L, Avanzo M, Furlan C, Fiorica F, Perin T, Militello L, Spazzapan S, Berretta M, Jena R, Stancanello J, Piccoli E, Mileto M, Micheli E, Roncadin M, Massarut S and Trovò M: Ten daily fractions for partial breast irradiation. Long-term results of a prospective phase II trial. Breast J 25(2): 243-249, 2019. PMID: 30714257. DOI: 10.1111/tbj.13195

16 Meattini I, Marrazzo L, Saieva C, Desideri I, Scotti V, Simontacchi G, Bonomo P, Greto D, Mangoni M, Scoccianti S, Lucidi S, Paoletti L, Fambrini M, Bernini M, Sanchez L, Orzalesi L, Nori J, Bianchi S, Pallotta S and Livi L: Accelerated partial-breast irradiation compared with whole-breast irradiation for early breast cancer: Long-term results of the randomized phase III APBI-IMRT-florence trial. J Clin Oncol 38(35): 41754183, 2020. PMID: 32840419. DOI: 10.1200/JCO.20.00650

17 Brunt AM, Haviland JS, Sydenham M, Agrawal RK, Algurafi H, Alhasso A, Barrett-Lee P, Bliss P, Bloomfield D, Bowen J, Donovan E, Goodman A, Harnett A, Hogg M, Kumar S, Passant H, Quigley M, Sherwin L, Stewart A, Syndikus I, Tremlett J, Tsang Y, Venables K, Wheatley D, Bliss JM and Yarnold JR: Tenyear results of FAST: A randomized controlled trial of 5-fraction whole-breast radiotherapy for early breast cancer. J Clin Oncol 38(28): 3261-3272, 2020. PMID: 32663119. DOI: 10.1200/ JCO.19.02750

18 Murray Brunt A, Haviland JS, Wheatley DA, Sydenham MA, Alhasso A, Bloomfield DJ, Chan C, Churn M, Cleator S, Coles CE, Goodman A, Harnett A, Hopwood P, Kirby AM, Kirwan CC, Morris C, Nabi Z, Sawyer E, Somaiah N, Stones L, Syndikus I, Bliss JM, Yarnold JR and FAST-Forward Trial Management Group.: Hypofractionated breast radiotherapy for 1 week versus 3 weeks (FAST-Forward): 5-year efficacy and late normal tissue effects results from a multicentre, non-inferiority, randomised, phase 3 trial. Lancet 395(10237): 1613-1626, 2020. PMID: 32580883. DOI: 10.1016/S0140-6736(20)30932-6

19 Guenzi M, Vagge S, Azinwi NC, D’Alonzo A, Belgioia L, Garelli S, Gusinu M and Corvò R: A biologically competitive 21 days hypofractionation scheme with weekly concomitant boost in breast cancer radiotherapy feasibility acute sub-acute and short term late effects. Radiat Oncol 5: 111, 2010. PMID: 21092219. DOI: $10.1186 / 1748-717 X-5-111$

20 Guenzi M, Bonzano E, Corvò R, Merolla F, Pastorino A, Cavagnetto F, Garelli S, Cutolo CA, Friedman D and Belgioia L: Comparison of local recurrence among early breast cancer patients treated with electron intraoperative radiotherapy $v s$. hypofractionated photon radiotherapy an observational study. Front Oncol 8: 207, 2018. PMID: 29922596. DOI: 10.3389/ fonc.2018.00207

21 Bonzano E, Belgioia L, Polizzi G, Siffredi G, Fregatti P, Friedman D, Garelli S, Gusinu M, Vaccara EML, Guenzi M and Corvò R: Simultaneous integrated boost in once-weekly hypofractionated radiotherapy for breast cancer in the elderly: Preliminary evidence. In Vivo 33(6): 1985-1992, 2019. PMID: 31662528. DOI: $10.21873 /$ invivo.11694

22 NCCN Guidelines. Available at: http://www.nccn.org/professionals/ physician_gls/pdf/breast.pdf [Last accessed on June 14 2021]

23 Krug D, Baumann R, Combs SE, Duma MN, Dunst J, Feyer P, Fietkau R, Haase W, Harms W, Hehr T, Piroth MD, Sedlmayer F, Souchon R, Strnad V, Budach W and Breast Cancer Expert Panel of the German Society of Radiation Oncology (DEGRO): Moderate hypofractionation remains the standard of care for whole-breast radiotherapy in breast cancer: Considerations regarding FAST and FAST-Forward. Strahlenther Onkol 197(4): 269-280, 2021. PMID: 33507331. DOI: 10.1007/s00066-020-01744-3

24 De Felice F, Ranalli T, Musio D, Lisi R, Rea F, Caiazzo R and Tombolini V: Relation between hypofractionated radiotherapy, toxicity and outcome in early breast cancer. Breast J 23(5): 563568, 2017. PMID: 28252236. DOI: 10.1111/tbj.12792

25 Iatì G, Pontoriero A, Mondello S, Santacaterina A, Platania A, Frosina P, Raso MM, Aiello D, Arcudi A, Arena G, Marino G, Mazzei M, Rifatto C, Risoleti E, Runco R, Sansotta G, Delia P, Sindoni A and Pergolizzi S: Nodal ratio as a prognostic factor in patients with four or more positive axillary nodes treated with breast-conserving therapy and regional nodal irradiation. Anticancer Res 36(7): 3549-3554, 2016. PMID: 27354622

26 Palumbo I, Mariucci C, Falcinelli L, Perrucci E, Lancellotta V, Podlesko AM, Marcantonini M, Saldi S, Bini V and Aristei C: Hypofractionated whole breast radiotherapy with or without hypofractionated boost in early stage breast cancer patients: a mono-institutional analysis of skin and subcutaneous toxicity. Breast Cancer 26(3): 290-304, 2019. PMID: 30341747. DOI: 10.1007/s 12282-018-0923-Z

27 Corvò R, Lamanna G, Vagge S, Belgioia L, Bosetti D, Aloi D, Timon $G$ and Bacigalupo A: Once-weekly stereotactic radiotherapy for patients with oligometastases: compliance and preliminary efficacy. Tumori 99(2): 159-163, 2013. PMID: 23748808. DOI: $10.1700 / 1283.14186$

28 Bartelink H, Horiot JC, Poortmans PM, Struikmans H, Van den Bogaert W, Fourquet A, Jager JJ, Hoogenraad WJ, Oei SB, Wárlám-Rodenhuis $\mathrm{CC}$, Pierart $\mathrm{M}$ and Collette L: Impact of a higher radiation dose on local control and survival in breastconserving therapy of early breast cancer: 10 -year results of the randomized boost versus no boost EORTC 22881-10882 trial. J Clin Oncol 25(22): 3259-3265, 2007. PMID: 17577015. DOI: 10.1200/JCO.2007.11.4991

Received May 3, 2021

Revised June 9, 2021

Accepted June 16, 2021 